\title{
An algorithm with strong convergence for the split common fixed point problem of total asymptotically strict pseudocontraction mappings
}

Zhaoli Ma ${ }^{1}$ and Lin Wang ${ }^{2 *}$

"Correspondence:

WL64mail@aliyun.com

${ }^{2}$ College of Statistics and

Mathematics, Yunnan University of

Finance and Economics, Longquan

Road, Kunming, 650221, China

Full list of author information is

available at the end of the article

\begin{abstract}
The purpose of this paper is to propose an algorithm to solve the split common fixed point problems for total asymptotically strict pseudocontraction mappings in Hilbert spaces. Without the assumption of semi-compactness on the mappings, the iterative scheme is shown to converge strongly to a split common fixed point of such mappings. The results presented in the paper improve and extend some recent corresponding results.

MSC: $47 \mathrm{H} 09 ; 47 J 25$
\end{abstract}

Keywords: split common fixed point problem; split feasibility problem; total asymptotically strict pseudocontraction mapping; Hilbert space

\section{Introduction}

Let $H_{1}$ and $H_{2}$ be two real Hilbert spaces, $C$ and $Q$ be nonempty closed convex subsets of $H_{1}$ and $H_{2}$, respectively. The split feasibility problem is formulated as finding a point $q \in H_{1}$ with the properties

$$
q \in C \text { and } A q \in Q \text {, }
$$

where $A: H_{1} \rightarrow H_{2}$ is a bounded linear operator. Assuming that SFP (1.1) is consistent (i.e., (1.1) has a solution), it is not hard to see that $x \in C$ solve (1.1) if and only if it solves the following fixed point equation:

$$
x=P_{C}\left(I-\gamma A^{*}\left(I-P_{Q}\right) A\right) x, \quad x \in C,
$$

where $P_{C}$ and $P_{Q}$ are the (orthogonal) projections onto $C$ and $Q$, respectively, $\gamma>0$ is any positive constant, and $A^{*}$ denotes the adjoint of $A$. The split feasibility problem in finite dimensional Hilbert spaces was introduced by Censor and Elfving [1] in 1994 for modeling inverse problems which arise from phase retrievals and in medical image reconstruction [2]. Recently, it has been found that split feasibility problems can be used in various disciplines, such as image restoration, computer tomography and radiation therapy treatment planning [3-7]. The split feasibility problem in Hilbert space can be found

(c) $2015 \mathrm{Ma}$ and Wang; licensee Springer. This is an Open Access article distributed under the terms of the Creative Commons Attribution License (http://creativecommons.org/licenses/by/4.0), which permits unrestricted use, distribution, and reproduction in any medium, provided the original work is properly credited. 
in $[2,4,6,8,9]$. Also the convex feasibility formalism is at the core of the modeling of many inverse problems and has been used to model significant real-world problems. The split common fixed point problem is a generalization of the split feasibility problem and the convex feasibility problem. If $C$ and $Q$ are the sets of fixed points of two nonlinear mappings, respectively, and $C$ and $Q$ are nonempty closed convex subsets, then $q$ is said to be a split common fixed point for the two nonlinear mappings. The split common fixed point problem (SCFP) for mappings $S$ and $T$ is to find a point $q \in H_{1}$ with the properties

$$
q \in F(S) \text { and } A q \in F(T)
$$

we use $\Gamma$ to denote the set of solutions of $\operatorname{SCFP}(1.3)$, that is, $\Gamma=\{q \in F(S): A q \in F(T)\}$.

Let $H$ be a real Hilbert space, $C$ be a nonempty and closed convex subset of $H$. A mapping $T: C \rightarrow C$ is said to be a $k$-strictly pseudocontractive mapping, if there exists $k \in[0,1)$ such that

$$
\|T x-T y\|^{2} \leq\|x-y\|^{2}+k\|(I-T) x-(I-T) y\|^{2}, \quad \forall x, y \in C .
$$

A mapping $T: C \rightarrow C$ is said to be $\left(k,\left\{k_{n}\right\}\right)$-asymptotically strictly pseudocontractive, if there exist a constant $k \in[0,1)$ and a sequence $\left\{k_{n}\right\} \subset[1, \infty)$ with $k_{n} \rightarrow 1$ such that

$$
\left\|T^{n} x-T^{n} y\right\|^{2} \leq k_{n}\|x-y\|^{2}+k\left\|\left(I-T^{n}\right) x-\left(I-T^{n}\right) y\right\|^{2}, \quad \forall x, y \in C .
$$

A mapping $T: C \rightarrow C$ is said to be $\left(k,\left\{\mu_{n}\right\},\left\{\xi_{n}\right\}, \phi\right)$-totally asymptotically strictly pseudocontractive, if there exist a constant $k \in[0,1)$ and sequences $\left\{\mu_{n}\right\} \subset[0, \infty)$ and $\left\{\xi_{n}\right\} \subset$ $[0, \infty)$ with $\mu_{n} \rightarrow 0$ and $\xi_{n} \rightarrow 0$ such that for all $x, y \in C$,

$$
\begin{aligned}
\left\|T^{n} x-T^{n} y\right\|^{2} \leq & \|x-y\|^{2}+k\left\|\left(I-T^{n}\right) x-\left(I-T^{n}\right) y\right\|^{2} \\
& +\mu_{n} \phi(\|x-y\|)+\xi_{n}, \quad \forall n \geq 1,
\end{aligned}
$$

where $\phi:[0, \infty) \rightarrow[0, \infty)$ is a continuous and strictly increasing function with $\phi(0)=0$.

Now, we give two examples of $\left(k,\left\{\mu_{n}\right\},\left\{\xi_{n}\right\}, \phi\right)$-total asymptotically strict pseudocontraction mappings.

Example 1.1 Let $C$ be a unit ball in a real Hilbert space $l^{2}$ and let $S: C \rightarrow C$ be a mapping defined by

$$
S:\left(x_{1}, x_{2}, \ldots\right) \rightarrow\left(0, x_{1}^{2}, a_{2} x_{2}, a_{3} x_{3}, \ldots\right)
$$

where $\left\{a_{i}\right\}$ is a sequence in $(0,1)$ such that $\prod_{i=2}^{\infty} a_{i}=\frac{1}{2}$.

It is proved by Goebel and Kirk [10] that

(i) $\|S x-S y\| \leq 2\|x-y\|, \forall x, y \in C$;

(ii) $\left\|S^{n} x-S^{n} y\right\| \leq 2 \prod_{j=2}^{n} a_{j}\|x-y\|, \forall x, y \in C, \forall n \geq 2$.

Denote by $k_{1}^{\frac{1}{2}}=2, k_{n}^{\frac{1}{2}}=2 \prod_{j=2}^{n} a_{j}, n \geq 2$, then

$$
\lim _{n \rightarrow \infty} k_{n}=\lim _{n \rightarrow \infty}\left(2 \prod_{j=2}^{n} a_{j}\right)^{2}=1 .
$$


Letting $\mu_{n}=\left(k_{n}-1\right), \forall n \geq 1, \phi(t)=t^{2}, \forall t \geq 0, k=0$, and $\left\{\xi_{n}\right\}$ be a nonnegative real sequence with $\xi_{n} \rightarrow 0$, then $\forall x, y \in C, n \geq 1$, we have

$$
\left\|S^{n} x-S^{n} y\right\|^{2} \leq\|x-y\|^{2}+\mu_{n} \phi(\|x-y\|)+k\left\|x-y-\left(S^{n} x-S^{n} y\right)\right\|^{2}+\xi_{n} .
$$

Especially, as $a_{n+1}=2^{-\frac{1}{2^{n}}}, \prod_{j=2}^{n} a_{j}=\frac{1}{2}$.

Example 1.2 Let $D$ be an orthogonal subspace of $R^{n}$ with the norm $\|x\|=\sqrt{\sum_{i=1}^{n} x_{i}^{2}}$ and the inner product $\langle x, y\rangle=\sum_{i=1}^{n} x_{i} y_{i}$ for $x=\left(x_{1}, \ldots, x_{n}\right)$ and $y=\left(y_{1}, \ldots, y_{n}\right)$. For each $x=\left(x_{1}, x_{2}, \ldots, x_{n}\right) \in D$, we define a mapping $T: D \rightarrow D$ by

$$
T x= \begin{cases}\left(x_{1}, x_{2}, \ldots, x_{n}\right), & \text { if } \prod_{i=1}^{n} x_{i}<0 \\ \left(-x_{1},-x_{2}, \ldots,-x_{n}\right), & \text { if } \prod_{i=1}^{n} x_{i} \geq 0 .\end{cases}
$$

Next we prove that $T$ is a $\left(k,\left\{\mu_{n}\right\},\left\{\xi_{n}\right\}, \phi\right)$-total asymptotically strict pseudocontraction mapping.

In fact, for any $x, y \in D$, let $\mu_{n}=\left(k_{n}-1\right), \forall n \geq 1, \phi(t)=t^{2}, \forall t \geq 0, k=0$, and letting $\left\{\xi_{n}\right\}$ be a nonnegative real sequence with $\xi_{n} \rightarrow 0$, we have the following:

Case 1 . If $\prod_{i=1}^{n} x_{i}<0$ and $\prod_{i=1}^{n} y_{i}<0$, then we have $T^{n} x=x, T^{n} y=y$, and so inequality (1.6) holds.

Case 2. If $\prod_{i=1}^{n} x_{i}<0$, and $\prod_{i=1}^{n} y_{i} \geq 0$, then we have $T^{n} x=x, T^{n} y=(-1)^{n} y$. This implies that

$$
\left\{\begin{array}{l}
\left\|T^{n} x-T^{n} y\right\|^{2}=\left\|x-(-1)^{n} y\right\|^{2}=\|x\|^{2}+\|y\|^{2} \\
k_{n}\|x-y\|^{2}=k_{n}\left(\|x\|^{2}+\|y\|^{2}\right) \\
\left\|x-T^{n} x-\left(y-T^{n} y\right)\right\|^{2}=\left[1-(-1)^{n}\right]^{2}\|y\|^{2}
\end{array}\right.
$$

Therefore the inequality (1.6) holds.

Case 3. If $\prod_{i=1}^{n} x_{i} \geq 0$ and $\prod_{i=1}^{n} y_{i}<0$, then we have $T^{n} x=(-1)^{n} x, T^{n} y=y$. Therefore we obtain

$$
\left\{\begin{array}{l}
\left\|T^{n} x-T^{n} y\right\|^{2}=\left\|(-1)^{n} x-y\right\|^{2}=\|x\|^{2}+\|y\|^{2} \\
k_{n}\|x-y\|^{2}=k_{n}\left(\|x\|^{2}+\|y\|^{2}\right) \\
\left\|x-T^{n} x-\left(y-T^{n} y\right)\right\|^{2}=\left[1-(-1)^{n}\right]^{2}\|x\|^{2}
\end{array}\right.
$$

So the inequality (1.6) holds.

Case 4. If $\prod_{i=1}^{n} x_{i} \geq 0$ and $\prod_{i=1}^{n} y_{i} \geq 0$, then we have $T^{n} x=(-1)^{n} x, T^{n} y=(-1)^{n} y$. Hence we have

$$
\left\{\begin{array}{l}
\left\|T^{n} x-T^{n} y\right\|^{2}=\left\|(-1)^{n} x-(-1)^{n} y\right\|^{2}=\|x-y\|^{2}=\|x\|^{2}+\|y\|^{2}, \\
k_{n}\|x-y\|^{2}=k_{n}\left(\|x\|^{2}+\|y\|^{2}\right), \\
\left\|x-T^{n} x-\left(y-T^{n} y\right)\right\|^{2}=\left[1-(-1)^{n}\right]^{2}\|x-y\|^{2}=\left[1-(-1)^{n}\right]^{2}\left(\|x\|^{2}+\|y\|^{2}\right) .
\end{array}\right.
$$

Thus the inequality (1.6) still holds. Therefore the mapping $T$ defined by (1.7) is a $\left(k,\left\{\mu_{n}\right\},\left\{\xi_{n}\right\}, \phi\right)$-total asymptotically strict pseudocontraction mapping.

Remark 1.3 If $\phi(\lambda)=\lambda^{2}, \lambda \geq 0$, and $\xi_{n}=0$, then a $\left(k,\left\{\mu_{n}\right\},\left\{\xi_{n}\right\}, \phi\right)$-total asymptotically strictly pseudocontractive mapping is an $\left(k,\left\{k_{n}\right\}\right)$-asymptotically strict pseudocontractive mapping, where $k_{n}=1+\mu_{n}$. 
A mapping $T: C \rightarrow C$ is said to be $L$-Lipschitzian, if there exists a constant $L>0$, such that

$$
\|T x-T y\| \leq L\|x-y\|, \quad \forall x, y \in C \text { and } n \geq 1 .
$$

A mapping $T: C \rightarrow C$ is said to be uniformly $L$-Lipschitzian, if there exists a constant $L>0$, such that

$$
\left\|T^{n} x-T^{n} y\right\| \leq L\|x-y\|, \quad \forall x, y \in C \text { and } n \geq 1 .
$$

Recently, Chang et al. [11] proposed the following iterative algorithm for solving a split common fixed point problem for total asymptotically strict pseudocontraction mappings in the framework of infinite-dimensional Hilbert spaces:

$$
\left\{\begin{array}{l}
x_{1} \in H_{1} \quad \text { chosen arbitrary, } \\
u_{n}=x_{n}+\gamma A^{*}\left(T^{n}-I\right) A x_{n}, \\
x_{n+1}=\left(1-\alpha_{n}\right) u_{n}+\alpha_{n} S^{n}\left(u_{n}\right), \quad n \in N
\end{array}\right.
$$

they proved that $\left\{x_{n}\right\}$ converges weakly to a split common fixed point $x^{*}$ of the mappings $S$ and $T$, where $S: H_{1} \rightarrow H_{1}$ and $T: H_{2} \rightarrow H_{2}$ are two total asymptotically strict pseudocontraction mappings, $A: H_{1} \rightarrow H_{2}$ is a bounded linear operator. In addition, they also show that $\left\{x_{n}\right\}$ converges strongly to a split common fixed point $x^{*}$ for mappings $S$ and $T$ when $S$ is semi-compact.

Inspired and motivated by the recent work of Chang et al. [11], Moudafi [12, 13], etc., the purpose of this paper is to propose an algorithm to solve the split common fixed point problems for total asymptotically strict pseudocontraction mappings in Hilbert spaces. Under suitable conditions on the control parameters and without the assumption of semicompactness on the mappings, a strong convergence theorem is established. The results presented in the paper improve and extend some recent corresponding results in $[4,5,8$, $11-15]$.

\section{Preliminaries}

Throughout this paper, let $H$ be a Hilbert space with inner product $\langle\cdot, \cdot\rangle$ and norm $\|\cdot\|$. We denote the strong convergence and weak convergence of a sequence $\left\{x_{n}\right\}$ to a point $x \in H$ by $x_{n} \rightarrow x, x_{n} \rightarrow x$, respectively.

Let $H$ be a Hilbert space. A mapping $T: H \rightarrow H$ is said to be demi-closed at origin, if for any sequence $\left\{x_{n}\right\} \subset H$ with $x_{n} \rightarrow x^{*}$ and $\left\|(I-T) x_{n}\right\| \rightarrow 0$, then $x^{*}=T x^{*}$.

A mapping $T: C \rightarrow C$ is said to be semi-compact, if for any bounded sequence $\left\{x_{n}\right\} \subset C$ with $\lim _{n \rightarrow \infty}\left\|x_{n}-T x_{n}\right\|=0$, then there exists a subsequence $\left\{x_{n_{i}}\right\} \subset\left\{x_{n}\right\}$ such that $\left\{x_{n_{i}}\right\}$ converges strongly to some point $x^{*} \in C$.

For every point $x \in H$, there exists a unique nearest point of $C$, denoted by $P_{C} x$, such that $\left\|x-P_{C} x\right\| \leq\|x-y\|$ for all $y \in C$. Such a $P_{C}$ is called the metric projection from $H$ onto $C$. It is well known that $P_{C}$ is a firmly nonexpansive mapping from $H$ to $C$, i.e.,

$$
\left\|P_{C} x-P_{C} y\right\|^{2} \leq\left\langle P_{C} x-P_{C} y, x-y\right\rangle, \quad \forall x, y \in H .
$$


Further, for any $x \in H$ and $z \in C, z=P_{C} x$ if and only if

$$
\langle x-z, z-y\rangle \geq 0, \quad \forall y \in C
$$

Lemma 2.1 ([16]) Let $C$ be a nonempty closed convex subset of a real Hilbert space $H$ and $P_{C}: H \rightarrow C$ be the metric projection from $H$ onto $C$. Then the following inequality holds:

$$
\left\|y-P_{C}(x)\right\|^{2}+\left\|x-P_{C}(x)\right\|^{2} \leq\|x-y\|^{2}, \quad \forall y \in C, \forall x \in H .
$$

Lemma 2.2 ([17]) Let $H$ be a real Hilbert space, then the following equalities hold:

(i) $\|\lambda x+(1-\lambda) y\|^{2}=\lambda\|x\|^{2}+(1-\lambda)\|y\|^{2}-\lambda(1-\lambda)\|x-y\|^{2}, \forall x, y \in H, \forall \lambda \in R$;

(ii) $2\langle x, y\rangle=\|x\|^{2}+\|y\|^{2}-\|x-y\|^{2}, \forall x, y \in H$.

Lemma 2.3 ([18]) Let $H$ be a real Hilbert space. If $\left\{x_{n}\right\}$ is a sequence in $H$, weakly convergent to $z$, then

$$
\limsup _{n \rightarrow \infty}\left\|x_{n}-y\right\|^{2}=\limsup _{n \rightarrow \infty}\left\|x_{n}-z\right\|^{2}+\|z-y\|^{2}, \quad \forall y \in H .
$$

Lemma 2.4 ([12]) Let $T: C \rightarrow C$ be a $\left(\rho,\left\{\mu_{n}\right\},\left\{\xi_{n}\right\}, \phi\right)$-total asymptotically strictly pseudocontractive mapping. If $F(T) \neq \emptyset$, then for each $q \in F(T)$ and for each $x \in C$, the following equivalent inequalities hold:

$$
\begin{aligned}
& \left\|T^{n} x-q\right\|^{2} \leq\|x-q\|^{2}+\rho\left\|x-T^{n} x\right\|^{2}+\mu_{n} \phi(\|x-q\|)+\xi_{n}, \\
& \left\langle x-T^{n} x, x-q\right\rangle \geq \frac{1-\rho}{2}\left\|x-T^{n} x\right\|^{2}-\frac{\mu_{n}}{2} \phi(\|x-q\|)-\frac{\xi_{n}}{2}, \\
& \left\langle x-T^{n} x, q-T^{n} x\right\rangle \leq \frac{\rho+1}{2}\left\|T^{n} x-x\right\|^{2}+\frac{\mu_{n}}{2} \phi(\|x-q\|)+\frac{\xi_{n}}{2} .
\end{aligned}
$$

Lemma 2.5 ([12]) Let $H$ be a real Hilbert space and let $T: H \rightarrow H$ be a uniformly L-Lipschitzian and $\left(k,\left\{\mu_{n}\right\},\left\{\xi_{n}\right\}, \phi\right)$-total asymptotically strictly pseudocontractive mapping. Then the demi-closedness principle holds for $T$ in the sense that if $\left\{x_{n}\right\}$ is a sequence in $H$ such that $x_{n} \rightarrow x^{*}$, and $\lim \sup _{m \rightarrow \infty} \limsup _{n \rightarrow \infty}\left\|x_{n}-T^{m} x_{n}\right\|=0$, then $(I-T) x^{*}=0$. In particular, if $x_{n} \rightarrow x^{*}$, and $\left\|(I-T) x_{n}\right\| \rightarrow 0$, then $(I-T) x^{*}=0$, i.e., $T$ is demi-closed at the origin.

\section{Main results}

Theorem 3.1 Let $H_{1}$ and $H_{2}$ be two real Hilbert spaces, and $A: H_{1} \rightarrow H_{2}$ be a bounded linear operator, $S: H_{1} \rightarrow H_{1}$ be a uniformly L-Lipschitzian and $\left(\rho,\left\{\mu_{n}^{(1)}\right\},\left\{\xi_{n}^{(1)}\right\}, \phi_{1}\right)$ total asymptotically strict pseudocontraction mapping and $T: \mathrm{H}_{2} \rightarrow \mathrm{H}_{2}$ be a uniformly $\tilde{L}$-Lipschitzian and $\left(k,\left\{\mu_{n}^{(2)}\right\},\left\{\xi_{n}^{(2)}\right\}, \phi_{2}\right)$-total asymptotically strict pseudocontraction mapping satisfying $F(S) \neq \emptyset$ and $F(T) \neq \emptyset$, respectively. Let $\left\{x_{n}\right\}$ be a sequence generated by $x_{1} \in C_{1}=H_{1}$,

$$
\left\{\begin{aligned}
& y_{n}=\left(1-\alpha_{n}\right) z_{n}+\alpha_{n} S^{n}\left(z_{n}\right), \\
& z_{n}=x_{n}+\gamma A^{*}\left(T^{n}-I\right) A x_{n}, \quad \forall n \geq 1, \\
& C_{n+1}=\left\{v \in C_{n}:\left\|y_{n}-v\right\|^{2} \leq\left(1+\mu_{n} M^{*}\right)\left\|z_{n}-v\right\|^{2}+\mu_{n} \phi(M)+\xi_{n},\right. \\
&\left.\left\|z_{n}-v\right\|^{2} \leq\left(1+\gamma \mu_{n} M^{*}\|A\|^{2}\right)\left\|x_{n}-v\right\|^{2}+\gamma \mu_{n} \phi(M)+\gamma \xi_{n}\right\}, \\
& x_{n+1}= P_{C_{n+1}}\left(x_{1}\right),
\end{aligned}\right.
$$


where $\left\{\alpha_{n}\right\}$ is a sequence in $(0,1), \gamma$ is a positive constant, $\left\{\mu_{n}\right\},\left\{\xi_{n}\right\}$, and $\phi$ satisfy the following conditions:

(i) $\alpha_{n} \in(\delta, 1-\rho), \forall n \geq 1$ and $\gamma \in\left(0, \frac{1-k}{\|A\|^{2}}\right)$, where $\delta$ is a constant in $(0,1-\rho)$;

(ii) $\mu_{n}=\max \left\{\mu_{n}^{(1)}, \mu_{n}^{(2)}\right\}, \xi_{n}=\max \left\{\xi_{n}^{(1)}, \xi_{n}^{(2)}\right\}, n \geq 1$, and $\sum_{n=1}^{\infty} \mu_{n}<\infty, \sum_{n=1}^{\infty} \xi_{n}<\infty$;

(iii) $\phi=\max \left\{\phi_{1}, \phi_{2}\right\}$ and there exist two positive constants $M$ and $M^{*}$ such that $\phi(\lambda) \leq M^{*} \lambda^{2}$ for all $\lambda \geq M$.

If $\Gamma=\{p \in F(S): A p \in F(T)\} \neq \emptyset$, then the sequence $\left\{x_{n}\right\}$ converges strongly to a split common fixed point $x^{*} \in \Gamma$.

Proof We shall divide the proof into five steps.

Step 1. We first show that $C_{n}$ is closed and convex for each $n \geq 1$.

Since $C_{1}=H_{1}, C_{1}$ is closed and convex. Suppose that $C_{n}$ is closed and convex for some $n>1$. Since for any $v \in C_{n}$, we have

$$
\begin{aligned}
&\left\|y_{n}-v\right\|^{2} \leq\left(1+\mu_{n} M^{*}\right)\left\|z_{n}-v\right\|^{2}+\mu_{n} \phi(M)+\xi_{n} \\
& \Leftrightarrow \quad 2\left\langle\left(1+\mu_{n} M^{*}\right) z_{n}-y_{n}-\mu_{n} M^{*} v, v\right\rangle \\
& \quad \leq\left(1+\mu_{n} M^{*}\right)\left\|z_{n}\right\|^{2}-\left\|y_{n}\right\|^{2}+\mu_{n} \phi(M)+\xi_{n}
\end{aligned}
$$

and

$$
\begin{aligned}
&\left\|z_{n}-v\right\|^{2} \leq\left(1+\gamma \mu_{n} M^{*}\|A\|^{2}\right)\left\|x_{n}-v\right\|^{2}+\gamma \mu_{n} \phi(M)+\gamma \xi_{n} \\
&\left.\Leftrightarrow \quad 2 /\left(1+\gamma \mu_{n} M^{*}\|A\|^{2}\right) x_{n}-z_{n}-\gamma \mu_{n} M^{*}\|A\|^{2} v, v\right\rangle \\
& \quad \leq\left(1+\gamma \mu_{n} M^{*}\|A\|^{2}\right)\left\|x_{n}\right\|^{2}-\left\|z_{n}\right\|^{2}+\gamma \mu_{n} \phi(M)+\gamma \xi_{n},
\end{aligned}
$$

hence the set $C_{n+1}$ is closed and convex. Therefore $C_{n}$ is closed and convex for each $n \geq 1$, and $P_{C_{n+1}} x_{1}$ is well defined.

Step 2. We show that $\Gamma \subset C_{n}$ for all $n \geq 1$.

In fact, since $\phi$ is a continuous and increasing function, $\phi(\lambda) \leq \phi(M)$, if $\lambda \leq M$, and $\phi(\lambda) \leq M^{*} \lambda^{2}$, if $\lambda \geq M$. In either case, we can obtain

$$
\phi(\lambda) \leq \phi(M)+M^{*} \lambda^{2}, \quad \forall \lambda \geq 0
$$

For any given $p \in \Gamma$, then $p \in F(S)$ and $A p \in F(T)$. It follows from (3.1) that

$$
\begin{aligned}
\left\|z_{n}-p\right\|^{2} & =\left\|x_{n}-p+\gamma A^{*}\left(T^{n}-I\right) A x_{n}\right\|^{2} \\
& =\left\|x_{n}-p\right\|^{2}+\gamma^{2}\left\|A^{*}\left(T^{n}-I\right) A x_{n}\right\|^{2}+2 \gamma\left\langle x_{n}-p, A^{*}\left(T^{n}-I\right) A x_{n}\right\rangle,
\end{aligned}
$$

where

$$
\begin{aligned}
2 \gamma & \left\langle x_{n}-p, A^{*}\left(T^{n}-I\right) A x_{n}\right\rangle \\
& =2 \gamma\left(A x_{n}-A p,\left(T^{n}-I\right) A x_{n}\right\rangle \\
& =2 \gamma\left(A x_{n}-A p+\left(T^{n}-I\right) A x_{n}-\left(T^{n}-I\right) A x_{n},\left(T^{n}-I\right) A x_{n}\right\rangle \\
& =2 \gamma\left\{\left\langle T^{n} A x_{n}-A p, T^{n} A x_{n}-A x_{n}\right\rangle-\left\|\left(T^{n}-I\right) A x_{n}\right\|^{2}\right\}
\end{aligned}
$$




$$
\begin{aligned}
& \leq 2 \gamma\left[\frac{1+k}{2}\left\|\left(T^{n}-I\right) A x_{n}\right\|^{2}+\frac{\mu_{n}}{2} \phi\left(\left\|A x_{n}-A p\right\|\right)+\frac{\xi_{n}}{2}-\left\|\left(T_{n}^{n}-I\right) A x_{n}\right\|^{2}\right] \\
& \leq \gamma(k-1)\left\|y\left(T_{n}^{n}-I\right) A x_{n}\right\|^{2}+\gamma \mu_{n} M^{*}\|A\|^{2}\left\|x_{n}-p\right\|^{2}+\gamma \mu_{n} \phi(M)+\gamma \xi_{n} .
\end{aligned}
$$

Substituting (3.6) into (3.5), we have

$$
\begin{aligned}
\left\|z_{n}-p\right\|^{2}= & \left\|x_{n}-p+\gamma A^{*}\left(T^{n}-I\right) A x_{n}\right\|^{2} \\
\leq & \left\|x_{n}-p\right\|^{2}+\gamma^{2}\left\|A^{*}\left(T^{n}-I\right) A x_{n}\right\|^{2}+\gamma(k-1)\left\|\left(T^{n}-I\right) A x_{n}\right\|^{2} \\
& +\gamma \mu_{n} M^{*}\|A\|^{2}\left\|x_{n}-p\right\|^{2}+\gamma \mu_{n} \phi(M)+\gamma \xi_{n} \\
\leq & \left\|x_{n}-p\right\|^{2}+\gamma^{2}\|A\|^{2}\left\|T^{n} A x_{n}-A x_{n}\right\|^{2}+\gamma(k-1)\left\|\left(T^{n}-I\right) A x_{n}\right\|^{2} \\
& +\gamma \mu_{n} M^{*}\|A\|^{2}\left\|x_{n}-p\right\|^{2}+\gamma \mu_{n} \phi(M)+\gamma \xi_{n} \\
= & \left(1+\gamma \mu_{n} M^{*}\|A\|^{2}\right)\left\|x_{n}-p\right\|^{2}-\gamma\left(1-k-\gamma\|A\|^{2}\right)\left\|T^{n} A x_{n}-A x_{n}\right\|^{2} \\
& +\gamma \mu_{n} \phi(M)+\gamma \xi_{n} .
\end{aligned}
$$

On the other hand, since

$$
\begin{aligned}
\left\|y_{n}-p\right\|^{2}= & \left\|z_{n}-p-\alpha_{n}\left(z_{n}-S^{n} z_{n}\right)\right\|^{2} \\
= & \left\|z_{n}-p\right\|^{2}-2 \alpha_{n}\left\langle z_{n}-p, z_{n}-S^{n} z_{n}\right\rangle+\alpha_{n}^{2}\left\|z_{n}-S^{n} z_{n}\right\|^{2} \\
\leq & \left\|z_{n}-p\right\|^{2}-\alpha_{n}(1-\rho)\left\|z_{n}-S^{n} z_{n}\right\|^{2} \\
& +\alpha_{n} \mu_{n} \phi\left(\left\|z_{n}-p\right\|\right)+\alpha_{n} \xi_{n}+\alpha_{n}^{2}\left\|z_{n}-S^{n} z_{n}\right\|^{2} \\
\leq & \left\|z_{n}-p\right\|^{2}-\alpha_{n}\left(1-\rho-\alpha_{n}\right)\left\|z_{n}-S^{n} z_{n}\right\|^{2} \\
& +\alpha_{n} \mu_{n}\left(\phi(M)+M^{*}\left(\left\|z_{n}-p\right\|\right)^{2}\right)+\alpha_{n} \xi_{n} \\
= & \left(1+\alpha_{n} \mu_{n} M^{*}\right)\left\|z_{n}-p\right\|^{2}-\alpha_{n}\left(1-\rho-\alpha_{n}\right)\left\|z_{n}-S^{n} z_{n}\right\|^{2} \\
& +\alpha_{n} \mu_{n} \phi(M)+\alpha_{n} \xi_{n},
\end{aligned}
$$

so, it follows from (3.7) and (3.8) that $p \in C_{n}$, and then $\Gamma \subset C_{n}$ for any $n \geq 1$.

Step 3. We prove that $\left\{x_{n}\right\}$ is a Cauchy sequence.

From the definition of $C_{n+1}$, we know that $x_{n}=P_{C_{n}} x_{1}$. Since $\Gamma \subset C_{n+1} \subset C_{n}$, and $x_{n+1} \in$ $C_{n+1} \subset C_{n}, \forall n>1$, we have

$$
\left\|x_{n}-x_{1}\right\| \leq\left\|x_{n+1}-x_{1}\right\|
$$

and

$$
\left\|x_{n}-x_{1}\right\| \leq\left\|p-x_{1}\right\|, \quad \forall n \in N \text { and } p \in \Gamma .
$$

It means that $\left\{x_{n}\right\}$ is nondecreasing and bounded. So, $\lim _{n \rightarrow \infty}\left\|x_{n}-x_{1}\right\|$ exists. For $m>n$, by the definition of $C_{n}$, we have $x_{m}=P_{C_{m}} x_{1} \in C_{m} \subset C_{n}$, it from Lemma 2.1 that

$$
\left\|x_{m}-x_{n}\right\|^{2}+\left\|x_{1}-x_{n}\right\|^{2}=\left\|x_{m}-P_{C_{n}} x_{1}\right\|^{2}+\left\|x_{1}-P_{C_{n}} x_{1}\right\|^{2} \leq\left\|x_{m}-x_{1}\right\|^{2} .
$$


Since $\lim _{n \rightarrow \infty}\left\|x_{n}-x_{1}\right\|$ exists, from (3.11), we obtain $\lim _{n \rightarrow \infty}\left\|x_{n}-x_{m}\right\|=0$. Therefore $\left\{x_{n}\right\}$ is a Cauchy sequence.

Step 4. We prove that $\lim _{n \rightarrow \infty}\left\|z_{n}-S z_{n}\right\|=\lim _{n \rightarrow \infty}\left\|A x_{n}-T A x_{n}\right\|=0$.

Since $x_{n+1}=P_{C_{n+1}} x_{1} \in C_{n+1} \subset C_{n}$, we obtain

$$
\begin{aligned}
\left\|z_{n}-x_{n}\right\|^{2} \leq & \left\|z_{n}-x_{n+1}\right\|^{2}+\left\|x_{n+1}-x_{n}\right\|^{2}+2\left\|z_{n}-x_{n+1}\right\| \cdot\left\|x_{n+1}-x_{n}\right\| \\
\leq & {\left[\left(1+\gamma \mu_{n} M^{*}\|A\|^{2}\right)+1\right]\left\|x_{n+1}-x_{n}\right\|^{2}+\gamma \mu_{n} \phi(M)+\gamma \xi_{n} } \\
& +2 \sqrt{\left(1+\gamma \mu_{n} M^{*}\|A\|^{2}\right)\left\|x_{n+1}-x_{n}\right\|^{2}+\gamma \mu_{n} \phi(M)+\gamma \xi_{n}} \\
& \times\left\|x_{n+1}-x_{n}\right\|,
\end{aligned}
$$

since $\sum_{n=1}^{\infty} \mu_{n}<\infty, \sum_{n=1}^{\infty} \xi_{n}<\infty$, and $\lim _{n \rightarrow \infty}\left\|x_{n}-x_{m}\right\|=0$, therefore

$$
\lim _{n \rightarrow \infty}\left\|z_{n}-x_{n}\right\|=0
$$

And

$$
\begin{aligned}
\left\|y_{n}-x_{n}\right\|^{2} \leq & \left\|y_{n}-x_{n+1}\right\|^{2}+\left\|x_{n+1}-x_{n}\right\|^{2}+2\left\|y_{n}-x_{n+1}\right\|\left\|x_{n+1}-x_{n}\right\| \\
\leq & \left(1+\gamma \mu_{n} M^{*}\right)\left\|z_{n}-x_{n+1}\right\|^{2}+\mu_{n} \phi(M)+\xi_{n}+\left\|x_{n+1}-x_{n}\right\|^{2} \\
& +2\left\|y_{n}-x_{n+1}\right\|\left\|x_{n+1}-x_{n}\right\| \\
\leq & {\left[\left(1+\gamma \mu_{n} M^{*}\right)\left(1+\gamma \mu_{n} M^{*}\|A\|^{2}\right)+1\right]\left\|x_{n+1}-x_{n}\right\|^{2} } \\
& +\left[\left(1+\gamma \mu_{n} M^{*}\right) \gamma+1\right] \mu_{n} \phi(M)+\left[\left(1+\gamma \mu_{n} M^{*}\right) \gamma+1\right] \xi_{n} \\
& +2 \sqrt{\left(1+\gamma \mu_{n} M^{*}\right)\left\|z_{n}-x_{n+1}\right\|^{2}+\mu_{n} \phi(M)+\xi_{n}}\left\|x_{n+1}-x_{n}\right\|,
\end{aligned}
$$

by $\sum_{n=1}^{\infty} \mu_{n}<\infty, \sum_{n=1}^{\infty} \xi_{n}<\infty$, and $\lim _{n \rightarrow \infty}\left\|x_{n}-x_{m}\right\|=0$, we have

$$
\lim _{n \rightarrow \infty}\left\|y_{n}-x_{n}\right\|=0
$$

Further,

$$
\left\|z_{n}-y_{n}\right\| \leq\left\|z_{n}-x_{n}\right\|+\left\|x_{n}-y_{n}\right\| \rightarrow 0 \text {. }
$$

It follows from (3.7) that

$$
\begin{aligned}
& \gamma\left(1-k-\gamma\|A\|^{2}\right)\left\|T^{n} A x_{n}-A x_{n}\right\|^{2} \\
& \leq\left(1+\gamma \mu_{n} M^{*}\|A\|^{2}\right)\left\|x_{n}-p\right\|^{2}-\left\|z_{n}-p\right\|^{2}+\gamma \mu_{n} \phi(M)+\gamma \xi_{n} \\
& \leq\left\|x_{n}-z_{n}\right\|\left(\left\|x_{n}-p\right\|+\left\|z_{n}-p\right\|\right)+\gamma \mu_{n} M^{*}\|A\|^{2}\left\|x_{n}-p\right\|^{2} \\
& \quad+\gamma \mu_{n} \phi(M)+\gamma \xi_{n} .
\end{aligned}
$$

Since $\sum_{n=1}^{\infty} \mu_{n}<\infty, \sum_{n=1}^{\infty} \xi_{n}<\infty, \gamma\left(1-k-\gamma\|A\|^{2}\right)>0$, and $\left\{x_{n}\right\}$ is bounded, by (3.13) and (3.16), we get

$$
\lim _{n \rightarrow \infty}\left\|T^{n} A x_{n}-A x_{n}\right\|=0
$$


On the other hand, from (3.8), we have

$$
\begin{aligned}
& \alpha_{n}\left(1-\rho-\alpha_{n}\right)\left\|z_{n}-S^{n} z_{n}\right\|^{2} \\
& \quad \leq\left(1+\alpha_{n} \mu_{n} M^{*}\right)\left\|z_{n}-p\right\|^{2}-\left\|y_{n}-p\right\|^{2}+\alpha_{n} \mu_{n} \phi(M)+\alpha_{n} \xi_{n} \\
& \quad \leq\left\|z_{n}-y_{n}\right\|\left(\left\|z_{n}-p\right\|+\left\|y_{n}-p\right\|\right)+\alpha_{n} \mu_{n} M^{*}\left\|z_{n}-p\right\|^{2}+\alpha_{n} \mu_{n} \phi(M)+\alpha_{n} \xi_{n} .
\end{aligned}
$$

This together with the conditions (i), (ii), and $\left\{z_{n}\right\}$ being bounded, from (3.15) and (3.18), we have

$$
\lim _{n \rightarrow \infty}\left\|z_{n}-S^{n} z_{n}\right\|=0
$$

In addition, since $\left\|z_{n+1}-z_{n}\right\| \leq\left\|z_{n+1}-x_{n+1}\right\|+\left\|x_{n+1}-x_{n}\right\|+\left\|x_{n}-z_{n}\right\|$, this means that

$$
\lim _{n \rightarrow \infty}\left\|z_{n+1}-z_{n}\right\|=0
$$

Since $S$ is uniformly $L$-Lipschitzian continuous,

$$
\begin{aligned}
\left\|z_{n}-S z_{n}\right\| & \leq\left\|z_{n}-S^{n} z_{n}\right\|+\left\|S^{n} z_{n}-S z_{n}\right\| \\
& \leq\left\|z_{n}-S^{n} z_{n}\right\|+L\left\|S^{n-1} z_{n}-z_{n}\right\| \\
& \leq\left\|z_{n}-S^{n} z_{n}\right\|+L\left(\left\|S^{n-1} z_{n}-S^{n-1} z_{n-1}\right\|+\left\|S^{n-1} z_{n-1}-z_{n}\right\|\right) \\
& \leq\left\|z_{n}-S^{n} z_{n}\right\|+L^{2}\left\|z_{n}-z_{n-1}\right\|+L\left\|S^{n-1} z_{n-1}-z_{n-1}+z_{n-1}-z_{n}\right\| \\
& \leq\left\|z_{n}-S^{n} z_{n}\right\|+L(1+L)\left\|z_{n}-z_{n-1}\right\|+L\left\|z_{n-1}-S^{n-1} z_{n-1}\right\| .
\end{aligned}
$$

It follows from (3.19), (3.20), and (3.21) that

$$
\lim _{n \rightarrow \infty}\left\|z_{n}-S z_{n}\right\|=0
$$

Similarly, in the same way as above, from (3.17), we can also obtain

$$
\lim _{n \rightarrow \infty}\left\|A x_{n}-T A x_{n}\right\|=0
$$

Step 5. We prove that $\left\{x_{n}\right\}$ converges strongly to $x^{*} \in \Gamma$.

Since $\left\{x_{n}\right\}$ is a Cauchy sequence, we may assume that $x_{n} \rightarrow x^{*}$. Thus we have $z_{n} \rightarrow x^{*}$ from (3.13), which implies that $z_{n} \rightarrow x^{*}$. So it follows from (3.22) and Lemma 2.5 that $x^{*} \in F(S)$.

On the other hand, since $A$ is a bounded linear operator, we know that $\lim _{n \rightarrow \infty} \| A x_{n}-$ $A x^{*} \|=0$. Therefore, it follows from Lemma 2.5 and (3.23) that $A x^{*} \in F(T)$. This means that $x^{*} \in \Gamma$ and $\left\{x_{n}\right\}$ converges strongly to $x^{*} \in \Gamma$. The proof is completed.

The following result can be obtained from Theorem 3.1 immediately.

Corollary 3.2 Let $H_{1}$ and $H_{2}$ be two real Hilbert spaces, $A: H_{1} \rightarrow H_{2}$ be a bounded linear operator, $S: H_{1} \rightarrow H_{1}$ be a uniformly L-Lipschitzian and $\left(\rho,\left\{k_{n}^{(1)}\right\}\right)$-asymptotically strict 
pseudocontraction mapping and $T: H_{2} \rightarrow H_{2}$ be a uniformly $\tilde{L}$-Lipschitzian and $\left(k,\left\{k_{n}^{(2)}\right\}\right)$ asymptotically strict pseudocontraction mapping satisfying $F(S) \neq \emptyset$ and $F(T) \neq \emptyset$, respectively. Let $\left\{x_{n}\right\}$ be a sequence defined as follows: $x_{1} \in C_{1}=H_{1}$,

$$
\left\{\begin{aligned}
& y_{n}=\left(1-\alpha_{n}\right) z_{n}+\alpha_{n} S^{n}\left(z_{n}\right), \\
& z_{n}=x_{n}+\gamma A^{*}\left(T^{n}-I\right) A x_{n}, \quad \forall n \geq 1, \\
& C_{n+1}=\left\{v \in C_{n}:\left\|y_{n}-v\right\|^{2} \leq\left(1+\left(k_{n}-1\right) \alpha_{n}\right)\left\|z_{n}-v\right\|^{2},\right. \\
&\left.\quad\left\|z_{n}-v\right\|^{2} \leq\left(1+\left(k_{n}-1\right) \gamma\|A\|^{2}\right)\left\|x_{n}-v\right\|^{2}\right\}, \\
& x_{n+1}=P_{C_{n+1}}\left(x_{1}\right),
\end{aligned}\right.
$$

where $\left\{\alpha_{n}\right\}$ is a sequence in $(0,1), \gamma$ is a positive constant and $\left\{k_{n}\right\}$ satisfy the following conditions:

(i) $k_{n}=\max \left\{k_{n}^{(1)}, k_{n}^{(2)}\right\}$, and $\sum_{n=1}^{\infty}\left(k_{n}-1\right)<\infty$;

(ii) $\alpha_{n} \in(\delta, 1-\rho), \forall n \geq 1$ and $\gamma \in\left(0, \frac{1-k}{\|A\|^{2}}\right)$, where $\delta$ is a constant in $(0,1-\rho)$.

If $\Gamma \neq \emptyset$, then the sequence $\left\{x_{n}\right\}$ converges strongly to a split common fixed point $x^{*} \in \Gamma$.

Remark 3.3 Theorem 3.1 extends and improves the result of Chang et al. [11, 15] from weak convergence to strong convergence by using the modified iterative scheme that we propose.

Remark 3.4 In Theorem 3.1, as $S$ and $T$ are two nonexpansive mappings, demi-contractive mappings or asymptotically strict pseudocontraction mappings, we can also obtain similar results.

Example 3.5 Let $C$ and $S$ be the same as in Example 1.1, and $D$ and $T$ be the same as in Example 1.2. It is obvious that $F(T)=\{(0,0, \ldots, 0)\} \cup\left\{\left(x_{1}, x_{2}, \ldots, x_{n}\right): \prod_{i=1}^{n} x_{i}<0\right\}, F(S)=$ $\{(0,0, \ldots, 0, \ldots)\}, C$ and $D$ are nonempty closed convex subsets of $l^{2}$ and $R^{n}$, respectively. Let $A: C \rightarrow D$ be defined by $A x=\left(x_{1}, x_{2}, \ldots, x_{n}\right)$ for $x=\left(x_{1}, x_{2}, \ldots\right) \in C$. Then $A$ is a bounded linear operator with adjoint operator $A^{*} z=\left(x_{1}, x_{2}, \ldots, x_{n}, 0,0, \ldots\right)$ for $z=\left(x_{1}, x_{2}, \ldots, x_{n}\right) \in D$. Clearly, $\|A\|=\left\|A^{*}\right\|=1$. By using algorithm (3.1) with $\frac{1}{4}<\alpha_{n}<\frac{3}{4}$ and $\gamma \in(0,1)$. We can verify $x_{n} \rightarrow(0,0, \ldots) \in F(S)$ and $A(0,0, \ldots)=(0,0, \ldots, 0) \in F(T)$.

\section{Applications}

\subsection{Application to hierarchical variational inequality problem}

Let $H$ be a real Hilbert space, $T$ and $S$ be two nonexpansive mappings from $H$ to $H$ such that $F(T) \neq \emptyset$ and $F(S) \neq \emptyset$.

The so-called hierarchical variational inequality problem for nonexpansive mapping $T$ with respect to nonexpansive mapping $S: H \rightarrow H$ is to find a point $x^{*} \in F(S)$ such that

$$
\left\langle x^{*}-T x^{*}, x^{*}-x\right\rangle \leq 0, \quad \forall x \in F(S) .
$$

It is easy to see that (4.1) is equivalent to the following fixed point problem:

$$
\text { find } x^{*} \in F(S) \text { such that } x^{*}=P_{F(S)} T x^{*} \text {, }
$$

where $P_{F(S)}$ is the metric projection from $H$ onto $F(S)$. Letting $C:=F(S)$ and $Q:=F\left(P_{F(S)} T\right)$ (the fixed point set of the mapping $\left.P_{F(S)} T\right)$ and $A=I$ (the identity mapping on $H$ ), then 
the problem (4.2) is equivalent to the following split feasibility problem:

$$
\text { find } x^{*} \in C \text { such that } A x^{*} \in Q \text {. }
$$

Hence from Theorem 3.1 we have the following theorem.

Theorem 4.1 Let $H, S, T, C$, and $Q$ be the same as above. Let $\left\{x_{n}\right\}$ be a sequence generated by $x_{1} \in C_{1}=H_{1}$,

$$
\left\{\begin{array}{l}
y_{n}=\left(1-\alpha_{n}\right) z_{n}+\alpha_{n} S z_{n}, \\
z_{n}=x_{n}+\gamma(T-I) x_{n}, \quad \forall n \geq 1, \\
C_{n+1}=\left\{v \in C_{n}:\left\|y_{n}-v\right\| \leq\left\|z_{n}-v\right\| \leq\left\|x_{n}-v\right\|\right\} \\
x_{n+1}=P_{C_{n+1}}\left(x_{1}\right),
\end{array}\right.
$$

where $\gamma \in(0,1)$ and $\left\{\alpha_{n}\right\}$ is a sequence in $(0,1)$ satisfying $\liminf _{n \rightarrow \infty} \alpha_{n}\left(1-\alpha_{n}\right)>0$. If $C \cap$ $Q \neq \emptyset$, then the sequence $\left\{x_{n}\right\}$ converges strongly to a solution of the hierarchical variational inequality problem (4.1).

Proof Since $S$ is nonexpansive, it is uniformly $L$-Lipschitzian continuous and $\left(\rho,\left\{\mu_{n}^{(1)}\right\}\right.$, $\left.\left\{\xi_{n}^{(1)}\right\}, \phi_{1}\right)$-total asymptotically strict pseudocontractive with $L=1, \mu_{n}^{(1)}=0, \xi_{n}^{(1)}=0, \phi_{1}=0$. Again since $T$ is nonexpansive, it is uniformly $\tilde{L}$-Lipschitzian continuous and $\left(k,\left\{\mu_{n}^{(2)}\right\}\right.$, $\left.\left\{\xi_{n}^{(2)}\right\}, \phi_{2}\right)$-total asymptotically strict pseudocontractive with $\tilde{L}=1, \mu_{n}^{(2)}=0, \xi_{n}^{(2)}=0, \phi_{2}=0$. Therefore, all conditions in Theorem 3.1 are satisfied. The conclusions of Theorem $4.1 \mathrm{can}$ be obtained from Theorem 3.1.

\subsection{Application to quadratic minimization problem over a fixed point set}

Let $K: H \rightarrow H$ be a linear bounded $\eta$-strongly positive operator with $\eta>1$, i.e.,

$$
\langle K x, x\rangle \geq \eta\|x\|^{2} .
$$

Let $f: H \rightarrow H$ be a $\varrho$-contraction with $\varrho \in(0,1)$ and $\gamma \in\left(\varrho^{-1}\left(\eta-\eta^{-1}\right), \frac{\eta}{\varrho}\right), S: H \rightarrow H$ be a nonexpansive mapping with $F(S) \neq \emptyset$ and $T:=I-\eta(K-\gamma f)$ be a mapping from $H$ to $H$.

Lemma 4.2 ([19]) Assume A is a strongly positive linear bounded operator on a Hilbert space $H$ with coefficient $\bar{\gamma}>0$ and $0<\rho \leq\|A\|^{-1}$. Then $\|I-\rho A\| \leq 1-\rho \bar{\gamma}$.

Now we prove that $T: H \rightarrow H$ is a nonexpansive mapping. In fact, for $\forall x, y \in H, \gamma \in$ $\left(\varrho^{-1}\left(\eta-\eta^{-1}\right), \frac{\eta}{\varrho}\right)$, from Lemma 4.2 , we have

$$
\begin{aligned}
\|T x-T y\| & \leq\|(I-\eta K) x-(I-\eta K) y\|+\eta \gamma\|f(x)-f(y)\| \\
& \leq\|I-\eta K\|\|x-y\|+\eta \gamma \varrho\|x-y\| \\
& \leq\left(1-\eta^{2}+\eta \gamma \varrho\right)\|x-y\| \\
& \leq\|x-y\| .
\end{aligned}
$$

Then the hierarchical variational inequality problem (4.1) reduces to finding $x^{*} \in F(S)$ such that

$$
\left\langle(K-\gamma f) x^{*}, x-x^{*}\right\rangle \geq 0, \quad \forall x \in F(S) .
$$


It is easy to see that (4.6) is exactly the optimality condition of the following quadratic minimization problem:

$$
\min _{x \in F(S)} \frac{1}{2}\{\langle K x, x\rangle-h(x)\}
$$

where $h$ is the potential for $\gamma f$, i.e., $h^{\prime}(x)=\gamma f$. Let $C=F(S), Q=F\left(P_{F(S)}(I-\eta(K-\gamma f))\right)$ and $A=I$, then the quadratic minimization problem (4.7) is equivalent to the following split feasibility problem:

$$
\text { find } x^{*} \in C \text { and such that } A x^{*} \in Q \text {. }
$$

Hence from Theorem 3.1 we have the following result.

Theorem 4.3 Let $H, K, f, S, T, C$, and $Q$ be the same as above. Let $\left\{x_{n}\right\}$ be a sequence generated by $x_{1} \in C_{1}=H_{1}$,

$$
\left\{\begin{array}{l}
y_{n}=\left(1-\alpha_{n}\right) z_{n}+\alpha_{n} S z_{n}, \\
z_{n}=x_{n}+\gamma(T-I) x_{n}, \quad \forall n \geq 1, \\
C_{n+1}=\left\{v \in C_{n}:\left\|y_{n}-v\right\| \leq\left\|z_{n}-v\right\| \leq\left\|x_{n}-v\right\|\right\} \\
x_{n+1}=P_{C_{n+1}}\left(x_{1}\right),
\end{array}\right.
$$

where $\gamma \in(0,1)$ and $\left\{\alpha_{n}\right\}$ is a sequence in $(0,1)$ satisfying $\liminf _{n \rightarrow \infty} \alpha_{n}\left(1-\alpha_{n}\right)>0$. If $C \cap$ $Q \neq \emptyset$, then the sequence $\left\{x_{n}\right\}$ converges strongly to a solution of problem (4.7).

\section{Competing interests}

The authors declare that they have no competing interests.

Authors' contributions

Both authors contributed equally to this work. Both authors read and approved the final manuscript.

\section{Author details}

'School of Information Engineering, College of Arts and Sciences, Yunnan Normal University, Longquan Road, Kunming, 650222, China. ${ }^{2}$ College of Statistics and Mathematics, Yunnan University of Finance and Economics, Longquan Road, Kunming, 650221, China.

\section{Acknowledgements}

The authors would like to express their thanks to the reviewers and editors for their helpful suggestions and advices. This work was supported by the National Natural Science Foundation of China (Grant No. 11361070).

Received: 1 May 2014 Accepted: 14 January 2015 Published online: 03 February 2015

\section{References}

1. Censor, Y, Elfving, T: A multiprojection algorithm using Bregman projection in a product space. Numer. Algorithms 8 , 221-239 (1994)

2. Byrne, C: Iterative oblique projection onto convex subsets and the split feasibility problems. Inverse Probl. 18 441-453 (2002)

3. Censor, $Y$, Bortfeld, T, Martin, B, Trofimov, T: A unified approach for inversion problem in intensity-modolated radiation therapy. Phys. Med. Biol. 51, 2353-2365 (2006)

4. Censor, Y, Elfving, T, Kopf, N, Bortfeld, T: The multiple-sets split feasibility problem and its applications. Inverse Probl. 21, 2071-2084 (2005)

5. Censor, Y, Motova, A, Segal, A: Pertured projections and subgradient projections for the multiple-sets split feasibility problems. J. Math. Anal. Appl. 327, 1244-1256 (2007)

6. Xu, HK: A variable Krasnosel'skii-Mann algorithm and the multiple-set split feasibility problem. Inverse Probl. 22 2021-2034 (2006)

7. Lopez, G, Martin, V, Xu, HK: Iterative algorithms for the multiple-sets split feasibility problem. In: Censor, Y, Jiang, M, Wang, G (eds.) Biomedical Mathematics: Promising Directions in Imaging, Therapy Planning and Inverse Problems, pp. 243-279. Medical Physics Publishing, Madison (2009) 
8. Yang, Q: The relaxed CQ algorithm for solving the split feasibility problem. Inverse Probl. 20, 1261-1266 (2004)

9. Zhao, J, Yang, Q: Several solution methods for the split feasibility problem. Inverse Problems 21, 1791-1799 (2005)

10. Goebel, K, Kirk, WA: A fixed point theorem for asymptotically nonexpansive mappings. Proc. Am. Math. Soc. 35 , 171-174 (1972)

11. Chang, SS, Wang, L, Tang, YK, Yang, L: The split common fixed point problem for total asymptotically strictly pseudocontractive mappings. J. Appl. Math. 2012, Article ID 385638 (2012). doi:10.1155/2012/385638

12. Moudafi, A: The split common fixed point problem for demi-contractive mappings. Inverse Probl. 26, 055007 (2010)

13. Moudafi, A: A note on the split common fixed point problem for quasi-nonexpansive operators. Nonlinear Anal. 74 4083-4087 (2011)

14. $\mathrm{Xu}, \mathrm{HK}$ : Iterative methods for split feasibility problem in infinite-dimensional Hilbert spaces. Inverse Probl. 26, 105018 (2010)

15. Chang, SS, Cho, YJ, Kim, JK, Zhang, WB, Yang, L: Multiple-set split feasibility problems for asymptotically strict pseudocontractions. Abstr. Appl. Anal. 2012, Article ID 491760 (2012). doi:10.1155/2012/491760

16. Nakajo, K, Takahashi, W: Strongly convergence theorems for nonexpansive mappings and nonexpansive semigroups. J. Math. Anal. Appl. 279, 372-379 (2003)

17. Marino, G, Xu, HK: Weak and strong convergence theorems for strict pseudocontractions in Hilbert spaces. J. Math. Anal. Appl. 329, 336-346 (2007)

18. Martinez-Yanes, C, Xu, HK: Strong convergence of the CQ method for fixed point processes. Nonlinear Anal. TMA 64 2400-2411 (2006)

19. Marino, G, Xu, HK: A general iterative method for nonexpansive mappings in Hilbert spaces. J. Math. Anal. Appl. 318 43-52 (2006)

\section{Submit your manuscript to a SpringerOpen ${ }^{\circ}$ journal and benefit from:}

- Convenient online submission

- Rigorous peer review

Immediate publication on acceptance

- Open access: articles freely available online

- High visibility within the field

- Retaining the copyright to your article 